\title{
Proteomic Approach to Discover Potential Biomarkers for Heart
}

\section{Failure}

Keywords: Biomarkers; Differentially expressed proteins; Unique proteins; Cellular cell stress; Mitochondrial dysfunction; Heart failure

\begin{abstract}
Heart failure is a clinical syndrome that develops due to abnormality in the cardiac structure or mechanical function leading to failure of the heart to deliver oxygen at a rate proportionate with the requirements of the metabolizing tissues. Despite advancement in primary prevention and therapy, it had continued to record poor prognosis and more complications leading to high rate of mortality. Recent advances in proteomic technologies permit the evaluation of systemic changes in protein expression in response to intrinsic or extrinsic perturbations to the biologic system. Proteomics is a potential tool for the discovery and application of novel biomarkers in diagnosis of the inception and progression of cardiovascular diseases (CVDs) which might then affect prevention and therapy. Shotgun proteomic approach was utilized to identify and compare the proteins in the tissue samples of a 3 month old glucokinase knockout mouse in early stage heart failure with a normal control mouse tissue sample. Bioinformatics analysis was performed using the MASCOT MS/MS ions search to identify, characterize and quantify. A total of 156 cardiac proteins were found in the normal control mouse tissue sample while 163 cardiac proteins were found in the diseased mouse tissue sample. $104 \mathrm{common}$ cardiac proteins were identified in both mouse tissue samples. 35 cardiac proteins out of the common cardiac proteins were differentially expressed in the diseased mouse tissue sample and 49 unique cardiac proteins were also found in the diseased mouse tissue sample. 6 cardiac proteins (ATP Synthase mitochondrial OS, Cytochrome C somatic OS, Myoglobin OS, Myosin-6 OS, Isocitrate dehydrogenase (NADP) mitochondrial OS and Histone $\mathrm{H} 4 \mathrm{OS}$ with high exponentially modified protein abundance index (emPAl) from the differentially expressed and unique cardiac proteins were selected as potential discovered biomarkers. The selected proteins play an important role in cellular stress response, mitochondrial dysfunction and myocardial cell death
\end{abstract}

\section{Introduction}

Heart Failure (HF) is a clinical syndrome frequently associated with impairment of the metabolizing tissues as a result of a defective heart. It remains the most well-known, expensive, disabling and deadly medical conditions encountered in primary and secondary care; and despite advances in the understanding and treatment, it still has a poor prognosis. Over the last 10 years, the yearly number of hospitalizations for heart failure has expanded from roughly 550,000 to about 900,000 as a primary diagnosis and from 1.7 to 2.6 million as a secondary diagnosis [1]. In the United States, approximately $\$ 500$ million yearly is used on medications for the treatment of HF. In developed countries, the epidemiology of symptomatic heart failure is well understood; between $1 \%$ and $2 \%$ of the adult population have heart failure, although it affects mainly elderly individual; $6-10 \%$ of individual over the age of 65 years have the disorder [2]. The lifetime danger of developing heart failure is roughly one in five for a matured individual of 40 years $[3,4]$.

According to the 2014 Non-communicable Disease country
Proteomics \& Computational Biology

\section{Ogu AC, Chukwu CE and Okeylbeh B}

Department of Medical Biotechnology, National Biotechnology Development Agency, Nigeria

\section{*Address for Correspondence}

Amoge Chidinma Ogu, National Biotechnology Development Agency, Umar Musa Yar'adua Express Way, Lugbe, Abuja, PMB 5118 WUSE ZONE 3, Nigeria, Tel: 2348063586783; Email: amosmeks@yahoo.com, a.c.ogu@nabda.gov.ng

Submission: 10 April, 2017

Accepted: 14 September, 2018

Published: 24 September, 2018

Copyright: () 2018 Ogu AC, et al. This is an open access article distributed under the Creative Commons Attribution License, which permits unrestricted use, distribution, and reproduction in any medium, provided the original work is properly cited.

profile by WHO, In Nigeria, Cardiovascular diseases (CVDs) accounts for $7 \%$ of total deaths which is more higher than Cancer $3 \%$ and Diabetes $2 \%$ respectively which makes it the leading cause of mortality in Nigeria. A study conducted in South Western Nigeria revealed that; of the 1004 cardiovascular disease patients recorded between 1997 and 2001, those with heart failure had the highest occurrence 384(35\%) while congenital heart disease has the Slowest occurrence $9.0(0.8 \%)$ [5]. In that study hypertension accounted for 353(32\%), stroke 192(17.4\%), cardiomyopathies $84(7.6 \%)$ and others $62(5.6 \%)$ [5].The study further revealed that men 671(60.8\%) were found to have higher incidence of cardiovascular disorders than women 633(39.2\%) [5]. The existence of ethnic differences was confirmed in hypertension control and in cardiovascular and renal outcomes, which they attributed to factors such as biological, cultural, social, healthcare provider and healthcare system factors like insurance and access to care and medication [6].

Heart Failure is associated with several co-morbidity such as angina, high blood pressure, diabetes, smoking-related lung malady, renal dysfunction and age [7]. Metabolic abnormalities that characterize type 2 diabetes (T2D) have long been shown to induce molecular mechanisms that contribute to accelerated atherosclerosis progression [8]. Moreover, individuals with T2D have an increased risk of developing cardiovascular diseases and higher cardiovascular mortality rates compared with individuals without T2D [9]. In the pancreas, glucokinase (GK) determines the rate of glucose-stimulated insulin secretion (GSIS), whereas in the liver the rates of glucose utilization and glycogen synthesis are regulated by the GK activity. Thus, GK plays a critical role in the regulation of blood glucose by acting as the glucose sensor in both pancreas and liver [10,11]. In humans, heterozygous point mutations in the glucokinase (GK) gene result in reduced enzymatic activity and decreased insulin secretion, causing maturity onset diabetes of the young (MODY) with earlyonset and persistent hyperglycemia [12]. Reduced GK activity has been suggested to contribute to impaired insulin secretion, as well as 
to the abnormalities in hepatic glucose balance in humans with T2D [13-16].

In the Acute Decompensated Heart Failure National Registry (ADHERE), 30\% of hospitalized patients with acute HF had a history of chronic renal failure (serum creatinine level $>2 \mathrm{mg} / \mathrm{dl}$ ) [17]. It also showed that admission levels of serum creatinine and blood urea nitrogen were among the strongest independent risk predictors for in-hospital mortality. With regard to chronic HF, 16 reviewed studies focused on the association between renal impairment and mortality in $80,098 \mathrm{HF}$ patients. They also reported that $63 \%$ of HF patients had at least mild renal dysfunction, and in $20 \%$ it was moderate or severe [18]. Traditionally, scientists working on CVDs have relied on epidemiology associations to identify diagnostic and prognostic risk factors such as hypercholesterolemia and hypertension in populations [19].

Heart failure however, arises as a consequence of an abnormality in the cardiac structure, function, rhythm or conduction. The presence of signs and symptoms among patients is an indication of abnormality or disorder; neither of observed symptoms such as excessive tiredness, breathlessness, orthopnea, paroxysmal nocturnal dyspnea, abdominal discomfort and nausea is specific to heart failure. In assessments, abnormal features associated with heart failure are palpation, fainting or abnormal heart rhythm.

Recent advances in proteomic technologies permit the evaluation of systemic changes in protein expression in response to intrinsic or extrinsic perturbations to the biologic system most especially those that occur in cardiovascular disease [20]. Proteomics is a potential tool for the discovery and application of novel biomarkers in diagnosis of the inception and progression of CVDs which might then affect prevention and therapy [21]. Proteomics differs from traditional "protein chemistry" in that the latter studies mainly the chemical properties of specific families of proteins whereas proteomics studies the large-scale interaction of the protein repertoire within an organism, animal or human. Proteomic biomarkers also differ from traditional biochemical markers that we currently use clinically in that multiple interacting protein species are evaluated simultaneously to response of a cell or an organism to disease or adversities in the environment [22]. Biomarkers are diagnostic tool that may be detectable, measurable and elevated as an indicator of normal biological processes, abnormal levels of disorders, pathogenic processes or pharmacological responses to a therapeutic invention [23]. The total market value of biomarker in 2014 is $\$ 5.95$ billion and it is expected to reach $\$ 30$ billion in 2020 growing at CAGR (Compound Annual Growth Rate) of 16\% from 2014 to 2020. A recent article on cardiac biomarkers emphasizes the need for a cardiac biomarker that detects the presence of myocardial damage even before the reversible myocardial damage is induced, and thereby help identify the vulnerable patients before major events occur, permitting prior treatment [24]. Therefore early detection of CVD would allow implementation of early intervention strategies to delay or prevent disease progression, which will not only save costs for medical care but will also lead to improved prognosis and quality of life. This study identified and compared the proteins found in the model mouse in early stage heart failure with the normal control mouse heart tissue.

\section{Materials and Methods}

Reagents such as stacking buffer (1M Tris- $\mathrm{HCl} \mathrm{pH} \mathrm{6.8),} \mathrm{resolving}$ buffer (1M Tris-HCl pH8.8), Sodium Dodecyl Sulphate (1\%, SDS), Laemmli buffer (2X), Ammonium Persulphate (APS, 1.5\%), Running buffer (10X), $50 \mathrm{ml}$ Ammonium bicarbonate (50 mM), Iodoacetamide, trypsin solution, $10 \%$ resolving gel and stacking gel were prepared.

\section{Gel moulding}

The gel Cassette was set up and tested to ensure no leakage inbetween the glass plate. A comb was inserted in-between the two glass plates, the prepared resolving gel mixture pipetted immediately to avoid solidification. The mixture was immediately overlaid with water to flatten the surface by adding slowly to avoid mixing. The gel was allowed to polymerize for 45 minutes before the water was absorbed using a filter paper at the half of time. The stacking gel mixture was prepared and pipetted to fill up the already loaded gel cassette avoiding air bubbles. The gel was left to solidify within 45 mins. After the gel was moulded in the gel cassette, it was unclipped and kept in a refrigerator for SDS-PAGE analysis using the Tris/ glycine buffer system according to Laemmli [25].

\section{Tissue processing}

A Leica Cryostat was used to slice the frozen normal and knockout glucokinase mice heart tissue and collected in labelled clean Eppendorf tubes. The tubes were kept in an ice pack till processed.

\section{Preparation of tissue lysate}

Laemmli sample buffer (2X) concentrate was used for protein sample preparation to denature the proteins. The samples were mixed with the buffer, heated in a water bath and centrifuged at $14000 \mathrm{~g}$ for 5 mins. The supernatant was transferred to labelled clean tubes.

\section{Electrophoresis assembly and sample loading}

The gel cassette was assembled into a BIO RAD Mini-PROTEAN Tetra Vertical Electrophoresis Celltank. The inner chamber was filled up with prepared 10X Running buffer and the comb removed to expose the wells. The SeeBlue Plus2 Pre-stained standard and the samples were loaded into the wells. The electrophoresis was allowed to run for 1 hour at $120 \mathrm{~V}$. At the end of the electrophoresis, the gel was removed and inverted into an InstantBlue Coomassie staining solution for 1 hour 30 minutes to fix the proteins and improve the sensitivity and detection.

\section{In-Gel protein digestion for mass spectrometric analysis}

Rinsed stained gel was placed on a clean glass slab. The lanes containing the bands were excised into four sections using a clean scalpel. Each section of the excised bands were cut into cubes and transferred into labelled tubes. The gel pieces were de-stained with prepared $50 \mathrm{mM}$ Ammonium Bicarbonate for 15 minutes. The supernatant was decanted and replaced with Acetonitrile to dehydrate the gel cubes for 15 minutes at room temperature before decanting. $400 \mu \mathrm{L}$ of Dithiothreitol (DTT) was poured to cover the gel pieces followed by 1 hour incubation using a hot plate at $60^{\circ} \mathrm{C}$ for Disulphide reduction. After incubation, the supernatant was decanted and 400 $\mu \mathrm{l}$ of the prepared $100 \mathrm{mM}$ Iodoacetamide was added coupled with 30 minutes incubation in the dark at room temperature for Cysteine 


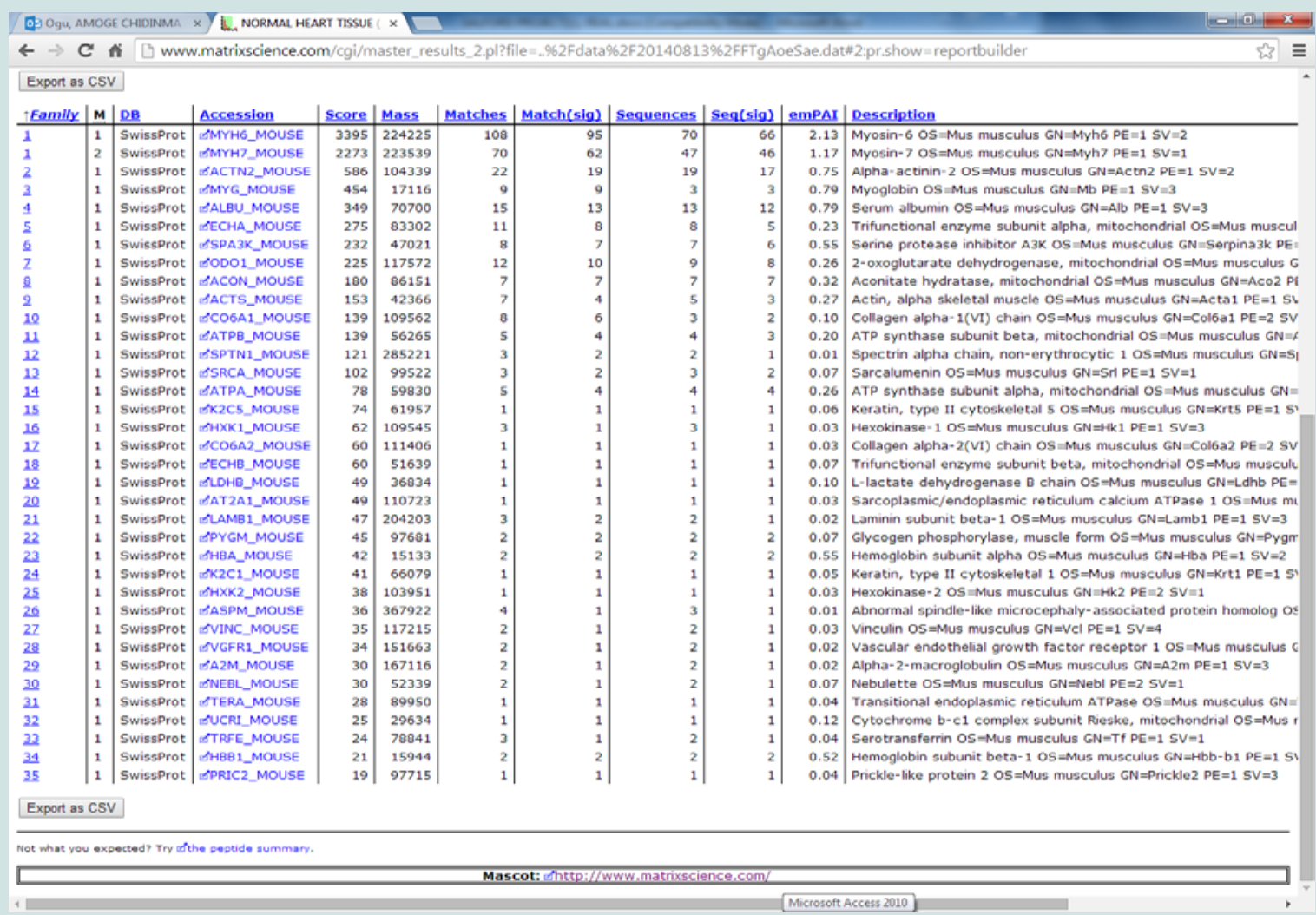

Figure 1: A list of the 36 protein hits revealing the family, Database, Accession, Score, Mass, Number of peptide matches (Matches), Number of Significant peptide matches (Matches(sig), Number of distinct sequences (Sequences), Number of significant distinct sequences (Seq (sig), Exponentially modified protein abundance index (emPAI) and Description. Each of the enlisted Accession possesses detail of the taxonomy, calculated isoelectric point and the point at which the trypsin enzyme cut.

alkylation to prevent re-oxidation. The supernatant was decanted and Acetonitrile was added and left for 5 minutes before decanting.

\section{Trypsin digestion}

Trypsin as an endoproteinase was added to the tubes containing the alkylated proteins in the gel pieces and incubated overnight at 37 ${ }^{\circ} \mathrm{C}$. It cleaves at the carboxylic side of lysine and arginine residues (that is to hydrolytically break the peptide). The distribution of Lys and Arg residues in proteins is such that trypsin digestion fragments the proteins in order to yield peptides of molecular weights that can be analysed by LC-MS/MS mass spectrometry.

\section{Bioinformatics analysis}

Bioformatic Analysis of the obtained MASCOT generic format data (mgf.data) was achieved by retrieveing the MASCOT software search engine from Matrix Science; a program for identifying, characterising and quantifying proteins using Mass Spectrometry data. A fresh work sheet for MASCOT MS/MS ions was retrieved, changes were made on the parameters such as; name,email address, Database to SwissProt, Enzyme left as Trypsin, Taxonomy to "Mus", Fixed modifications to Carbamidomethyl (C), Variable modifications to Oxidation (Methionine, M), data format to MASCOT generic and the already obtained data file was uploaded before clicking on the Start Search to commence the data retrieval. Through the protein family summary, the report builder was clicked for the fragment rf to load. The protein hits containing the family, database, accession, score, mass, number of peptide matches, no of significant peptide matches (Match, sig), number of distinct sequences, number of significant distinct sequences, Exponentially modified protein abundance index (emPAI) and description were revealed. This was repeated 8 times for all the mgf.data obtained from the trypsin digested 8 sample tubes analysed with LC-MS/MS Mass spectrometry.

\section{Results}

\section{SDS-PAGE separation}

The extracted proteins from the heart tissue samples of a normal mouse and a 3 months old glucokinase knockout mouse were separated using SDS-PAGE analysis. The bands were revealed on the lanes of gel which was an indication of the presence of separated proteins.

\section{Bioinformatics analysis}

The analysis showed a total of 156 cardiac proteins from the normal mouse tissue sample, 163 cardiac proteins were found in the glucokinase knockout mouse tissue sample, 104 common cardiac proteins were identified in both mice tissue samples while 35 cardaic proteins out of the common cardiac proteins were differentially expressed in the glucokinase knockout mouse tissue sample, 49 unique cardiac proteins were found in the glucokinase knockout mouse tissue sample and 13 Unique cardiac proteins found in the Normal Heart Control mouse (Figures 1 and 2). 6 cardiac proteins 


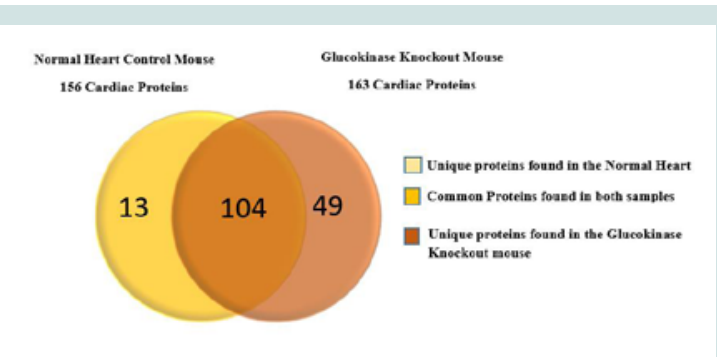

Figure 2: A Venn diagram of identified proteins identified from LC-MS/MS Mass spectrometry.

with high emPAI (exponentially modified protein abundance index) from the differentially expressed and unique cardiac proteins were finally selected as the final potential discovered biomarker for heart failure (Table 1). This confirms the role of biomarkers as a biological tool to monitor abnormal levels, predict the onset of a disease so as to delay or prevent disease progression and pharmacological responses to a therapeutic intervention and improved diagnosis.

\section{Discussion}

This study was designed to discover potential biomarkers for heart failure by identifying and comparing the proteins found in a glucokinase knockout mouse and normal mouse heart tissue samples in-order to understand its clinical relevance. The emPAI however, help to add value to quantitation in proteomic studies since it's proportional to the protein content in a protein mixture when applied to a protein expression analysis or when comparing a gene with a protein expression in a human or animal model (Figure 3). The Glucokinase also referred to as Hexokinase IV is encoded by a gene in rodents which controls beta cell insulin secretion and the absence of the glucokinase enzyme has been proven to cause diabetes or hyperglycemia due to the inability to control insulin which is a risk factor to developing heart failure overtime [26-29].

(Table 1) represents the selected proteins with High emPAI present in the tissue sample of 3 months old glucokinase-knockout mouse in early stage Heart failure. The protein ATP synthase subunit

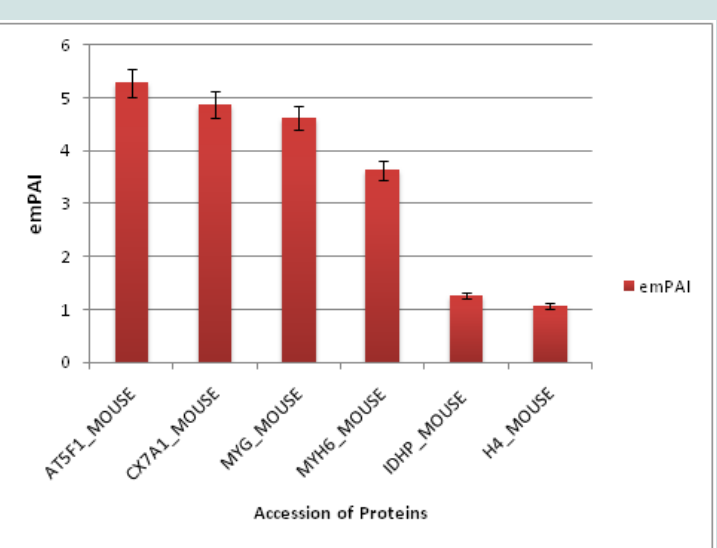

Figure 3: An illustration of the selected potential biomarkers and their rate of increase in emPAI scores. This chart illustrates that the protein with the Accession AT5F1 (ATP Synthase Subunit Beta) has the highest emPAI score of 5.29 while the protein with the Accession $\mathrm{H} 4$ (Histone $\mathrm{H} 4$ ) has the lowest emPAl score of 1.08 . $\beta$, mitochondrial OS with Accession AT5F1_MOUSE obtained from the Swissprot database has a Nominal mass (M) of 56265, high emPAI of 5.29, calculated Isoelectric point of 5.19 from Musmusculus. Adenosine-Triphosphate synthase is an essential component of mitochondrial energy conversion in the mammalian organism because it forms most of the cellular ATP in aerobic cells. Defects of this enzyme brings about mitochondrial diseases which are harmful and manifest primarily in children, very often shortly after birth [30]. The mitochondria are found in eukaryotes where it produces energy known as ATP in the cells; it is a vulnerable intracellular target to reactive oxidative-stress (ROS) induced injury [31,32]. Reactive oxygen has been considered to be important regulators of pathogenesis of pancreatitic oxidative stress which occur at the early stage of induction $[33,34]$.This injury are potential energy deficits that are important in the pancreas due to the energy demand for protein synthesis [35]. Changes in ATP synthase biogenesis may result to two types of isolated defects namely: qualitative (when the enzyme is structurally modified and does not function well) and quantitative when it is present in insufficient amounts. Cytochrome C, Somatic OS with Accession CX7A1_MOUSE is a unique protein found in the mouse model with high emPAI score of 4.87. In Apoptosis, it serves as a critical cell death factor capable of initiating the caspase cascade through the binding to apoptosis protease-activating factor, Apaf-1 and formation of apoptosomes [36]. Mueller and Driscoll, demonstrated that cytochrome c catalyzes the amidation of fatty acids and formation of important physiological regulators; long-chain fatty acyl glycines though the pathways are yet to be identified $[37,38]$. However, these biological activities of cytochrome $c$ are identified in its native state which successes has been recorded that the unfolding of cytochrome $c$ globule shows its function as a peroxidase [39]. This instability can be caused by chemical modification such as oxidation and nitration [40-42] or by the association of hydrophobic anions including phospholipids [43-49]. Myoglobin OS a differentially expressed protein with the Accession: MYG_MOUSE and emPAI score of 4.62 revealed the Nominal mass of 17116, Score of 712, calculated Isoelectric point (pI) of 7.07, protein sequence coverage of $59 \%$, number of peptide matches is 33 , number of significant peptide matches are 20, number of distinct sequences are 7 and number of significant distinct sequences are 7. Myoglobin is the earliest seen biochemical marker used for the assessment of patients with acute coronary syndrome. High scores of myoglobin protein is found in the blood stream after a skeletal muscle injury [50] and this is due to same amino acid composition of myoglobin found in cardiac and skeletal muscles which compromises the clinical specificity. A study demonstrated that a knockout mouse deficient of myoglobin showed $30 \%$ reduced volume of blood pumped by the heart during contraction which was due to the widening of the blood vessels (vasodilation) [51]. CHECKMATE study has proved that the presence of myoglobin brings about the presence of other markers in predicting the outcomes [52]. This indeed has played a role in adding diagnostic value in risk stratification of patients with acute coronary syndrome [53]. However, myoglobin is a sensitive marker for muscle injury that acts as a potential marker for heart attack in patients with chest pain [54]. In humans, oxygen reduction catalysis, dioxygen transport and storage are carried out by Hemoglobin, Myoglobin and cytochrome c oxidase [55-57]. Myosin-6 OS Accession MYH6_MOUSE a differentially expressed protein revealed an emPAI value of 3.64, 
Citation: Ogu AC, Chukwu CE, Okeylbeh B. Proteomic Approach to Discover Potential Biomarkers for Heart Failure. J Proteomics Computational Biol. 2018;4(1): 7

ISSN: 2572-8679

Table 1: Selected proteins with high emPAI present in the tissue sample from a 3 months old glucokinase-knockout mouse in early stage Heart failure.

\begin{tabular}{|l|c|c|c|}
\hline \multicolumn{1}{|c|}{ Accession } & Mass & emPAl & Description \\
\hline AT5F1_MOUSE & 56265 & $\mathbf{5 . 2 9}$ & ATP Synthase Subunit beta ,mitochondrial OS \\
\hline CX7A1_MOUSE & 11712 & $\mathbf{4 . 8 7}$ & CytochromeC, Somatic OS \\
\hline MYG_MOUSE & 17116 & $\mathbf{4 . 6 2}$ & Myoglobin OS \\
\hline MYH6_MOUSE & 224225 & $\mathbf{3 . 6 4}$ & Myosin-6 OS \\
\hline IDHP_MOUSE & 51330 & $\mathbf{1 . 2 7}$ & Isocitrate dehydrogenase (NADP) mitochondrial OS \\
\hline H4_MOUSE & 11360 & $\mathbf{1 . 0 8}$ & Histone H4 OS \\
\hline
\end{tabular}

Nominal mass of 224225, Score of 4281, Calculated Isoelectric point (pI) of 5.57, number of peptide matches of 136, number of significant peptide matches of 122 , number of distinct sequences of 65 and number of significant distinct sequences of 60 . MYH6 symbolizes the protein Myosin heavy chain 6, cardiac muscle, alpha. It is located in the cardiac muscle cells (heart) where it creates a force for contraction within the cardiac muscle permitting the heart to pump blood to every part of the body. Mutation in the MYH6 gene brings about modification in the myosin protein and this has been proven to cause various heart disorders like congenital heart defects(CHD) especially atrial-septal defect (ASD) which is a hole in the wall (septum) that separates the two upper chamber of the heart (atria) [58,59]. Modifications in this protein can cause dilated myopathy (DCM) and hypertrophic cardiomyopathy (HCM) [60,61]. DCM causes enlargement and weakening of the heart while HCM thickens the cardiac muscle (hypertrophy). All these conditions prevent the heart from pumping blood effectively and increase the risk of heart failure/ sudden death. Isocitrate dehydrogenase (NADP) mitochondrial OS (IDHP_MOUSE) showed an emPAI value of 1.27, Nominal mass of 51330 , Score of 373 , Calculated Isoelectric point (pI) of 8.88, protein sequence coverage of $26 \%$, number of peptide matches of 12 , number of significant peptide matches of 12 , number of distinct sequences of 11 and number of significant distinct sequences of 11. It is an enzyme found in the mitochondria where it produces energy for all cell activities [62]. In humans, it exists in three isoforms: IDH3 catalyzes the third step of citric acid cycle while converting NAD to NADH in the mitochondria. The isoform IDH1 and IDH2 catalyzes the same reaction outside the context of the citric acid cycle and uses NADP as a cofactor instead of NAD. Generally, Isocitrate dehydrogenase converts isocitrate to 2-ketoglutarate. The conversion reaction produces a molecule called NADPH which is necessary for many cellular processes and helps protect cells from potentially harmful molecules called reactive oxygen species [63]. Mutations in the IDH gene have been found to cause (D-2-HGA) type II and increase in the D-2-hydroxyglutarate obstruct the normal function of conversion of isocitrate to 2-ketoglutarate [64]. The altered enzyme takes an abnormal function of building up abnormal cells. At high levels, it causes cell damage which leads to cell death. People with this form of disorder also have a weakened and enlarged heart (cardiomyopathy). However, accumulation of D-2HGA in transgenic mice with activated two alleles has been proven to provoke dilated cardiomyopathy. The diseased hearts exhibited mitochondrial damage and glycogen accumulation with a concordant up-regulation of genes involved in glycogen biosynthesis [65]. Unique protein Histone H4 OS (Accession H4_MOUSE) revealed an emPAI value of 1.08, Nominal mass of 11360 , Score of 80 , Calculated Isoelectric point (pI) of 11.36, number of peptide matches of 3 , number of significant peptide matches of 3 , number of distinct sequences of 2 and number of significant distinct sequences of 2 . Histone 4 belongs to the 5histone proteins found in the nuclei of animals and plant cells that arrange the DNA into structural units known as nucleosomes [66]. They undergo modifications, acetylation, phosphorylation and methylation which might alter the expression of genes. Progress in cardiovascular research has uncovered that inflammation, proliferation and remodelling are gene-environmental interactions which play a role in epigenetic mechanisms such as histone acetylation and DNA methylation [67]. The association between histone acetylation and atherosclerosis was investigated using low-density lipoprotein (LDL) receptor deficient mice fed with an atherogenic diet for 4weeks [68]. It was observed that a specific histone deacetylase inhibitor (Trichostatin A) aggravated atherosclerosis. This finding however suggested that histone 4 acetylation played a role in atherogenesis and might have affected the progress of atherosclerosis [69].

\section{Conclusion}

Reactive Oxygen Species (ROS) in cardiovascular disease increases the level of lipid peroxides which results to structural changes in the heart. Cellular disruption due to oxidative stress and mitochondrial abnormality increases the progression of heart failure in humans. Therefore, the presence of these cardiac proteins has proven to be an indicator to aid diagnosis, prognosis and risk stratification of HF for evaluation of therapy. They are linked to cellular stress response (oxidative stress) and cardiac metabolism in the mitochondria. Early detection of Heart failure is essential and would permit implementation of early intervention strategies to delay or prevent disease progression. However there is need for collaborative work within the research community, healthcare system and policy makers to select and validate biomarkers that will improve heart failure care and general patient management in Non-communicable diseases.

\section{References}

1. Haldeman GA, Croft JB, Giles WH, Rashidee A (1999) Hospitalization of patients with heart failure: National Discharge Survey, 1985 to 1995. Am Heart J 137: 352-360.

2. Ho KK, Pinsky JL, Kannel WB, Levy D (1993) The epidemiology of heart failure: the framingham study. J Am Coll Cardiol 22 (4 Suppl A): 6A-13A.

3. Lloyd-Jones DM, Larson MG, Leip EP, Beiser A, D'Agostino RB, et al. (2002) Lifetime risk for developing congestive heart failure: the framingham heart study. Circulation 106: 3068-3072.

4. Bleumink GS, Knetsch AM, Sturkenboom MC, Straus SM, Hofman A, et al. (2004) Quantifying the heart failure epidemic: prevalence, incidence rate, lifetime risk and prognosis of heart failure the rotterdam study. Eur Heart $\mathrm{J}$ 25: 1614-1619.

5. Adedoyin R, Adesoye A (2005) Incidence and pattern of cardiovascular disease in a Nigerian teaching hospital. Trop Doc 35: 104-106.

6. Rehman SU, Hutchison FN, Hendrix K, Okonofua EC, Egan BM (2005) Ethnic differences in blood pressure control among men at veterans' affairs 
Citation: Ogu AC, Chukwu CE, Okeylbeh B. Proteomic Approach to Discover Potential Biomarkers for Heart Failure. J Proteomics Computational Biol. 2018;4(1): 7

ISSN: $2572-8679$

clinics and other health care sites. Arch 1ntern Med 165: 1041-1047.

7. Braunstein JB, Anderson GF, Gerstenblith G, Weller W, Niefeld M, et al. (2003) Noncardiac comorbidity increases preventable hospitalizations and mortality among Medicare beneficiaries with chronic heart failure. J Am Coll Cardiol 42: 1226-1233.

8. Creager MA, Luscher TF, Cosentino F, Beckman JA (2003) Diabetes and vascular disease: pathophysiology, clinical consequences, and medical therapy-part I. Circulation 108: 1527-1532.

9. Luscher T, Creager M, Beckman J, Cosentino F (2003). Diabetes and vascular disease: pathophysiology, clinical consequences, and medical therapy-part II. Circulation 108:1655-1661.

10. Coghlan M, Leighton B (2008) Glucokinase activators in diabetes management. Expert Opin Investig Drugs 17: 145-167.

11. Matschinsky FM (2009) Assessing the potential of glucokinase activators in diabetes therapy. Nat Rev Drug Discov 8: 399-416.

12. Osbak KK, Colclough K, Saint-Martin C, Beer NL, Bellanne-Chantelot C et al. (2009) Update on mutations in glucokinase (GCK), which cause maturity-onset diabetes of the young, permanent neonatal diabetes, and hyperinsulinemic hypoglycemia. Hum Mutat 30: 1512-1526.

13. Caro JF, Triester S, Patel VK, Tapscott EB, Frazier NL, et al. (1995) Liver glucokinase: decreased activity in patients with type II diabetes. Horm Metab Res 27: 19-22.

14. Basu A, Basu R, Shah P, Vella A, Johnson CM, et al. (2000) Effects of type 2 diabetes on the ability of insulin and glucose to regulate splanchnic and muscle glucose metabolism: evidence for a defect in hepatic glucokinase activity. Diabetes 49: 272-283.

15. Basu A, Basu R, Shah P, Vella A, Johnson CM, et al. (2001) Type 2 diabetes impairs splanchnic uptake of glucose but does not alter intestinal glucose absorption during enteral glucose feeding: additional evidence for a defect in hepatic glucokinase activity. Diabetes 50: 1351-1362.

16. Del Guerra S, Lupi R, Marselli L, Masini M, Bugliani M, et al. (2005) Functional and molecular defects of pancreatic islets in human type 2 diabetes. Diabetes 54: 727-735

17. Adams KF Jr, Fonarow GC, Emerman CL, LeJemtel TH, Costanzo MR, et al. (2005) Characteristics and outcomes of patients hospitalized for heart failure in the United States: rationale, design, and preliminary observations from the first 100,000 cases in the Acute Decompensated Heart Failure National Registry (ADHERE). Am Heart J 149: 209-216.

18. Smith GL, Lichtman JH, Bracken MB, Shlipak MG, Phillips CO, et al. (2006) Renal impairment and outcomes in heart failure: systematic review and meta-analysis. J Am Coll Cardiol 47: 1987-1996.

19. Schocken DD, Benjamin EJ, Fonarow GC, Krumholz HM, Levy D, et al (2008) Prevention of heart failure: a scientific statement from the American Heart Association councils on epidemiology and prevention, clinical cardiology, cardiovascular nursing, and high blood pressure research; quality of care and outcomes research interdisciplinary working group; and functional genomics and translational biology interdisciplinary working group. Circulation 117: 2544-2565.

20. Rocha M, Esplugues J, Hernandez-Mijares A, Victor VM (2009) Mitochondrial-targeted antioxidants and oxidative stress: a proteomic prospective study. Curr Pharm Des 15: 3052-3062.

21. Arab S, Gramolini AO, Ping P, Kislinger T, Stanley B, van Eyk, et al. (2006) Cardiovascular proteomics: tools to develop novel biomarkers and potential applications. J Am Coll Cardiol 48: 1733-1741.

22. McGregor E, Dunn MJ (2006) Proteomics of the heart: unraveling disease Circ Res 98: 309-321.

23. Jain KK (2010) Technologies for discovery of biomarkers. In: The handbook of biomarkers. Springer Nature, Switzerland, pp. 23-72.

24. Sadana A, Sadana N (2014) Biomarkers and biosensors: detection and binding to biosensor surfaces and biomarkers applications. pp. 702 .

25. Laemmli UK (1970) Cleavage of structural proteins during the assembly of the head of bacteriophage T4. Nature 227: 680-685.

26. Sakai K, Miyazaki Ji (1997) A transgenic mouse line that retains Cre recombinase activity in mature oocytes irrespective of the cre transgene transmission. Biochem Biophys Res Commun 237: 318-324.

27. Postic C, Shiota M, Niswender KD, Jetton TL, Chen Y, et al. (1999) Dual roles for glucokinase in glucose homeostasis as determined by liver and pancreatic beta cell specific gene knock-outs using Cre recombinase. J Biol Chem 274: 305-315.

28. Postic C, Niswender KD, Decaux JF, Parsa R, Shelton KD, et al. (1995) Cloning and characterization of the mouse glucokinase gene locus and identification of distal liver-specific DNase I hypersensitive sites. Genomics 29: $740-750$.

29. Niswender KD, Postic C, Jetton TL, Bennett BD, Piston DW, et al (1997) Cell-specific expression and regulation of a glucokinase gene locus transgene. J Biol Chem 272: 22564-22569.

30. Cahill A, Wang X, Hoek JB (1997) Increased oxidative damage to mitochondrial DNA following chronic ethanol consumption. Biochem Biophys Res Commun 235: 286-290.

31. Fernandez-Checa JC, Hirano T, Tsukamoto H, Kaplowitz N (1993) Mitochondrial glutathione depletion in alcoholic liver disease. Alcohol 10: 469-475.

32. Lieber CS (2000) Alcoholic liver disease: new insights in pathogenesis lead to new treatments. J Hepatol 32(1 Suppl): 113-128.

33. Schoenberg MH, Buchler M, Gaspar M, Stinner A, Younes M, et al. (1990) Oxygen free radicals in acute pancreatitis of the rat. Gut 31: 1138-1143.

34. Gough DB, Boyle B, Joyce WP, Delaney CP, McGeeney KF, et al. (1990) Free radical inhibition and serial chemiluminescence in evolving experimental pancreatitis. Br J Surg 77: 1256-1259.

35. Nonaka A, Manabe T, Tamura K, Asano N, Imanishi K, et al. (1990) Organ specific ESR features in mouse main organs and ESR application to the model of pancreatic disorders. Nihon Geka Gakkai Zasshi 1990: 169-173.

36. Liu X, Kim CN, Yang J, Jemmerson R, Wang X (1996) Induction of apoptotic program in cell-free extracts: requirement for dATP and cytochrome c. Cell 86: 147-157.

37. Mueller GP, Driscoll WJ (2007) In vitro synthesis of oleoylglycine by cytochrome $\mathrm{c}$ points to a novel pathway for the production of lipid signaling molecules. J Biol Chem 282: 22364-22369.

38. Driscoll WJ, Chaturvedi S, Mueller GP (2007) Oleamide synthesizing activity from rat kidney: identification as cytochrome c. J Biol Chem 282: 22353-22363.

39. Gebicka L (2001) Peroxidase-like activity of cytochrome $c$ in the presence of anionic surfactants. Res Chem Intermed 27: 717-723.

40. Santucci R, Brunori M, Ascoli F (1987) Unfolding and flexibility in hemoproteins shown in the case of carboxymethylated cytochrome c. Biochim Biophys Acta 914: 185-189.

41. Chen YR, Chen CL, Liu X, Li H, Zweier JL, et al. (2004) Involvement of protein radical, protein aggregation, and effects on $\mathrm{NO}$ metabolism in the hypochlorite-mediated oxidation of mitochondrial cytochrome c. Free Radic Biol Med 37: 1591-1603.

42. Abriata LA, Cassina A, Tortora V, Marin M, Souza JM, et al. (2008) Nitration of solvent-exposed tyrosine 74 on cytochrome $c$ triggers heme ironmethionine-80 bond disruption. Nuclear magnetic resonance and optical spectroscopy studies. J Biol Chem 284: 17-26.

43. Pinheiro TJ, Watts A (1994) Lipid specificity in the interaction of cytochrome $\mathrm{c}$ with an ionic phospholipid bilayers revealed by solid-state 31P NMR. Biochemistry 33: 2451-2458.

44. de Jongh HH, Ritsema T, Killian JA (1995) Lipid specificity for membrane mediated partial unfolding of cytochrome c. FEBS Lett 360: 255-260.

45. Sanghera N, Pinheiro TJ (2000) Unfolding and refolding of cytochrome c driven by the interaction with lipid micelles. Protein Sci 9: 1194-1202. 
Citation: Ogu AC, Chukwu CE, Okeylbeh B. Proteomic Approach to Discover Potential Biomarkers for Heart Failure. J Proteomics Computational Biol. 2018;4(1): 7 .

ISSN: $2572-8679$

46. Oellerich S, Lecomte S, Paternostre M, Heimburg T, Hildebrandt P (2004) Peripheral and integral binding of cytochrome $\mathrm{c}$ to phospholipids vesicles. J Phys Chem B 108: 3871-3878.

47. Belikova NA, Vladimirov YA, Osipov AN, Kapralov AA, Tyurin VA, et al. (2006) Peroxidase activity and structural transitions of cytochrome $c$ bound to cardiolipin-containing membranes. Biochemistry 45: 4998-5009.

48. Kapralov AA, Kurnikov IV, Vlasova II, Belikova NA, Tyurin VA, et al (2007) The hierarchy of structural transitions induced in cytochrome $c$ by anionic phospholipids determines its peroxidase activation and selective peroxidation during apoptosis in cells. Biochemistry 46: 14232-14244.

49. Sinibaldi F, Fiorucci L, Patriarca A, Lauceri R, Ferri T, et al. (2008) Insights into cytochrome c-cardiolipin interaction: role played by ionic strength. Biochemistry 47: 6928-6935.

50. Lehninger AL, Nelson DL, Cox MM (2000) Lehninger principles of biochemistry ( $3^{\text {rd }}$ edn). Worth Publishers, New York, USA, pp. 1152.

51. Mammen PP, Kanatous SB, Yuhanna IS, Shaul PW, Garry MG, et al (2003) Hypoxia-induced left ventricular dysfunction in myoglobin-deficient mice. Am J Physiol Heart Circ Physiol 285: 2132-2141.

52. Newby LK, Storrow AB, Gibler WB, Garvey JL, Tucker JF, et al. (2001) Bedside multimarker testing for risk stratification in chest pain units: the chest pain evaluation by creatine kinase-MB, myoglobin, and troponin (CHECKMATE) study. Circulation 103:1832-1837.

53. Hamm CW (2001) Acute coronary syndromes. The diagnostic role of troponins. Thrombosis Res 103: 63-69.

54. Weber M, Rau M, Madlener K, Elsaesser A, Bankovic D, et al. (2005) Diagnostic utility of new immunoassays for the cardiac markers $\mathrm{CTnl}$, myoglobin and CK-MB mass. Clin Biochem 38: 1027-1030.

55. Barrientos A, Barros MH, Valnot I, Rotig A, Rustin P, et al. (2002) Cytochrome oxidase in health and disease. Gene 286: 53-63.

56. Eaton WA, Henry ER, Hofrichter J, Mozzarelli A (1999) Is cooperative oxygen binding by hemoglobin really understood? Nat Struct Mol Biol 6 : 351-358.

57. Ordway G, Garry DJ (2004) Myoglobin: an essential hemoprotein in striated muscle. J Exp Biol 207: 3441-3446.
58. Granados-Riveron JT, Ghosh TK, Pope M, Bu'Lock F, Thornborough C, et al. (2010) Alpha-cardiac myosin heavy chain (MYH6) mutations affecting myofibril formation are associated with congenital heart defects. Hum Mol Genet 19: 4007-4016.

59. Posch MG, Waldmuller S, Muller M, Scheffold T, Fournier D, et al. (2011) Cardiac alpha-myosin (MYH6) is the predominant sarcomeric disease gene for familial atrial septal defects. PLoS One 6: e28872.

60. Hershberger RE, Norton N, Morales A, Li D, Siegfried JD, et al. (2010) Coding sequence rare variants identified in MYBPC3, MYH6, TPM1, TNNC1 and TNNI3 from 312 patients with familial or idiopathic dilated cardiomyopathy. Circ Cardiovasc Genet 3: 155-161.

61. Carniel E, Taylor MR, Sinagra G, Lenarda A, Ku L, et al. (2005) Alphamyosin heavy chain: a sarcomeric gene associated with dilated and hypertrophic phenotypes of cardiomyopathy. Circulation 112: $54-59$

62. Wallace DC (1999) Mitochondrial diseases in man and mouse. Science 283: $1482-1488$.

63. Houtkooper RK, Canto C, Wanders RJ, Auwerx J (2010) The secret life of NAD+: an old metabolite controlling new metabolic signaling pathways Endocr Rev 31: 194-223.

64. Pietrak B, Zhao H, Qi H, Quinn C, Gao E, et al. (2011) A tale of two subunits: how the neomorphic $\mathrm{R} 132 \mathrm{H} \mathrm{IDH} 1$ mutation enhances production of aHG. Biochemistry 50: 4804-4812.

65. Kranendijk M, Struys EA, van Schaftingen E, Gibson KM, Kanhai WA, et al. (2010) IDH2 mutations in patients with D-2-hydroxyglutaric aciduria. Science 330: 336.

66. Birge EA (2006) Fundamentals of bacterial and viral genetics. In: Bacterial and bacteriophage genetics. Springer Nature, Switzerland, pp. 1-29.

67. Jenuwein T, Allis CD (2001) Translating the histone code. Science 293 1074-1080.

68. Choi JH, Nam KH, Kim J, Baek MW, Park JE, et al. (2005) Trichostatin A exacerbates atherosclerosis in low density lipoprotein receptor-deficient mice. Arterioscler Thromb Vasc Biol 25: 2404-2409.

69. Marks PA, Richon VM, Rifkind RA (2000) Histone deacetylase inhibitors: inducers of differentiation or apoptosis of transformed cells. J Natl Cancer Inst 92: 1210-1216.

\section{Acknowledgement}

I acknowledge my supervisor; Dr. Nirmalan Niroshini, School of Environmenta and Life Sciences, University of Salford, Greater Manchester, United Kingdom. For her supervision, professionalism and intellectual contribution towards this research. I also wish to acknowledge my mentor Dr. Opeolu Ojo, School of Health, Sport and Biosciences, University of East London, United Kingdom for his support and intellectual contributions during this research and study. 